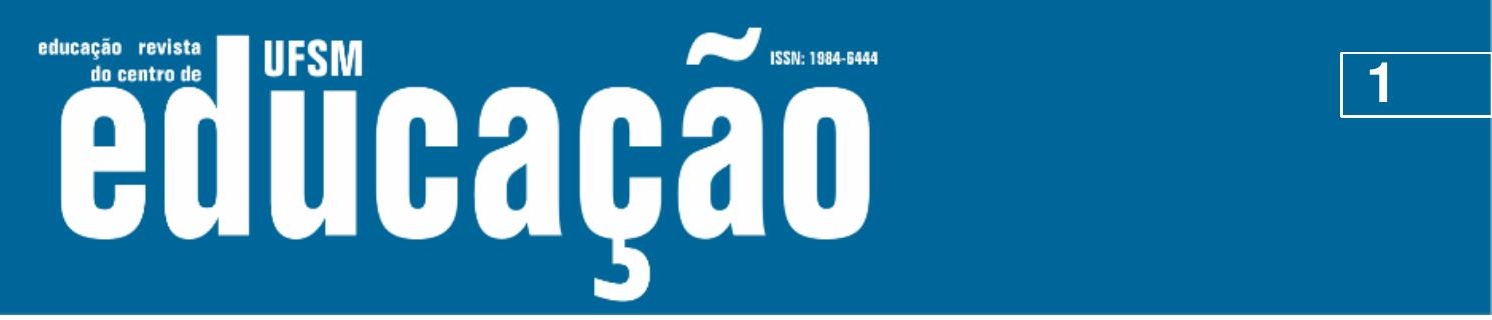

ISSN: 1984-6444 | http://dx.doi.org/10.5902/1984644437943

\title{
Educação e tecnologia: a crise da inteligência
}

\author{
Education and technology: the crisis of intelligence
}

\author{
* Maurício Rebelo Martins \\ Professor doutor na Universidade Federal da Paraíba. Bananeiras, Paraíba, Brasil. \\ maurebelo@gmail.com - https://orcid.org/0000-0003-0661-660X
}

Recebido em 02 de maio de 2019

Aprovado em 02 de junho de 2019

Publicado em 07 de agosto de 2019

\section{RESUMO}

Investiguei a relação entre a educação e tecnologia, argumentando acerca dos limites, desafios e possibilidades de enfrentamento do que chamamos de crise da inteligência. Meu objetivo é mostrar como as novas tecnologias vem transformando a forma como pensamos e agimos. Não são poucas as pesquisas e reflexões que mostram as influências negativas das novas tecnologias. Contudo, no campo educacional, são raros os trabalhos que procuram destacar essas dificuldades. Dessa forma, entendo a necessidade de refletir, investigar e argumentar sobre as consequências das novas tecnologias para a educação, amparando-se numa bibliografia específica a esse respeito. As novas tecnologias, a internet, por exemplo, são meios e não os fins da educação. Como meios, servem aos fins educacionais e não o contrário. Portanto, não se trata de proibir o acesso das novas gerações as novas tecnologias, mas de criar um espaço educacional onde elas possam desenvolver todas suas capacidades. $\mathrm{O}$ uso dessas tecnologias tem comprometido o desenvolvimento de importantes capacidades cognitivas como a memória, a imaginação e, também, a faculdade do pensar e cooperar. Para enfrentar esses desafios, revelando os resultados da pesquisa realizada, sugiro, no final do artigo, três medidas que podem ser implementadas imediatamente em nossas instituições educativas.

Palavras-chave: Educação; Tecnologia; Inteligência.

\section{ABSTRACT}

I investigated the relationship between education and technology, arguing about the limits, challenges and possibilities of coping with what we call the crisis of intelligence. My goal is to show how new technologies are transforming the way we think and act. There are many researches and reflections that show the negative influences of new technologies. However, in the educational field, there are few studies that attempt to highlight these difficulties. In this way, I understand the need to reflect, investigate and 


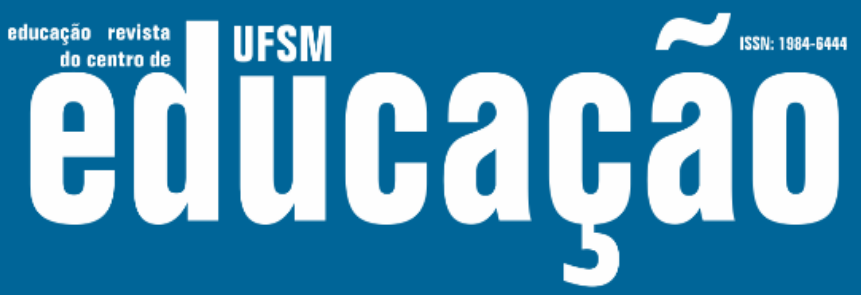

ISSN: 1984-6444 | http://dx.doi.org/10.5902/1984644437943

argue about the consequences of new technologies for education, based on a specific bibliography in this regard. New technologies, the internet, for example, are means and not the ends of education. As a means, they serve educational purposes, not vice versa. Therefore, it is not a question of prohibiting the access of new generations to new technologies, but of creating an educational space where they can develop all their capacities. The use of these technologies has compromised the development of important cognitive capacities such as memory, imagination and also the faculty of thinking and cooperating. To meet these challenges, revealing the results of the research, I suggest, at the end of the article, three measures that can be implemented immediately in our educational institutions.

Keywords: Education; Technology; Intelligence.

\section{Introdução}

A importância da educação sempre é lembrada nos discursos políticos e no dia nacional da hipocrisia: 15 de outubro. Dia no qual toda sociedade fala da importância da educação e dos professores. Contudo, nem sempre esses discursos representam um comprometimento verdadeiro com a transformação da realidade educacional. Vivemos uma época marcada por grandes e rápidas transformações. A globalização e as novas tecnologias da informação e comunicação aceleram essas transformações. Pensar a educação e suas instituições, nesse contexto, é uma tarefa extremamente difícil, mas necessária.

Estamos diante de uma geração muito diferente das anteriores. Criados na era da revolução digital, os jovens e crianças de hoje não pensam e agem da mesma forma como pensávamos e agíamos. Sendo assim, quando refletimos a educação e suas instituições, a primeira dificuldade surge na escolha entre adaptar a educação ao novo modelo de sociedade e à nova imagem de homem ou eleger uma educação conservadora, baseada em princípios tradicionais de organização e formação.

Geralmente a educação e suas instituições deixam-se orientar pelo consumo e pelo utilitarismo. Enquanto para o consumo o reconhecimento está associado à capacidade de acumular, para o utilitarismo o indivíduo é reconhecido pelo que ele faz profissionalmente. Entretanto, consumismo e utilitarismo não são os únicos aspectos da cultura contemporânea responsáveis pela atual situação da educação. 


\title{
T Nosm giturarao

ISSN: 1984-6444 | http://dx.doi.org/10.5902/1984644437943

Parafraseando Neil Postman (2002), outro deus assumiu lugar importante nessa crise: a tecnologia. É muito difícil separar no mundo contemporâneo consumo, utilitarismo e tecnologia. Tratam-se de três realidades que se entrecruzam na complexidade social.

Os avanços da ciência e tecnologia substituíram os deuses antigos. Nenhuma novidade até aqui, pois Heidegger (2007), Horkheimer (2002), Adorno (2006) e outros pensadores contemporâneos já denunciaram o perigo que o endeusamento da tecnologia poderia representar para a sobrevivência da humanidade. O impacto das novas tecnologias sobre a educação é algo novo que carece de cuidadoso exame para evitar a crítica unilateral dos riscos sem reconhecer os incontestáveis benefícios da tecnologia. Mesmo assim, talvez o alerta de Adorno (2006, p. 155) deva ser retomado:

\begin{abstract}
Entendo por barbárie algo muito simples, ou seja, que, estando na civilização do mais alto desenvolvimento tecnológico, as pessoas se encontrem atrasadas de um modo peculiarmente disforme em relação a sua própria civilização - e não apenas por não terem em sua arrasadora maioria experimentado a formação nos termos correspondentes ao conceito de civilização, mas também por se encontrarem tomadas por uma agressividade primitiva, um ódio primitivo ou, na terminologia culta, um impulso de destruição, que contribui para aumentar ainda mais o perigo de que toda esta civilização venha a explodir, aliás uma tendência imanente que a caracteriza. Considero tão urgente impedir isto que eu reordenaria todos os outros objetivos educacionais por esta prioridade.
\end{abstract}

Adorno destaca, nessa passagem, que a barbárie está ligada ao descompasso entre avanços tecnológicos e avanços humanos. Este descompasso, registrado por Adorno no tempo da Segunda Guerra mundial, tornou-se hoje endêmico e estrutural. Hoje depositamos mais confiança na tecnologia do que no nosso relacionamento com os outros. Nada vemos de estranho na criação de assentos aquecidos de vasos sanitários mesmo que muitas pessoas sequer tenham acesso ao saneamento básico. Não nos importam estas contradições quando se trata de promover o consumo. Investem-se grandes recursos para desenvolver novas e sofisticadas tecnologias que servem ao conforto de uns poucos, enquanto outros não conseguem satisfazer suas necessidades básicas.

No presente artigo, nosso objetivo é, num primeiro momento, abordar como essas novas tecnologias impactam sobre as sociedades do presente e, especialmente, analisar e discutir as consequências para educação. Quer dizer, 


\title{
T usm Eutua

ISSN: 1984-6444 | http://dx.doi.org/10.5902/1984644437943

tentaremos mostrar que mesmo com os benefícios, essas novas tecnologias têm contribuído para o que chamaremos de crise da inteligência. Por fim, esperamos apresentar algumas possibilidades de enfrentamento dessa crise.

\section{As novas tecnologias da informação e comunicação e o impacto sobre a educação}

Produção e consumo são os valores centrais das nossas sociedades. Em particular, o consumo da tecnologia vem alcançando o topo da lista de prioridades de qualquer indivíduo. A tecnologia oferece ao indivíduo algo que se busca desde os primórdios da humanidade: poder. Curiosamente, um reflexo do utilitarismo sobre a tecnologia é a exigência de possuir poder e praticidade. Ou seja, quanto mais avançado e impactante for um equipamento, mais sensação de poder ele agrega ao seu consumidor. Tal como os deuses na antiguidade, hoje o deus da tecnologia oferece uma série de recompensas:

\begin{abstract}
Oferece conforto, eficiência e prosperidade aqui e agora; e oferece seus benefícios a todos, aos ricos e também aos pobres, como o faz o Deus cristão. Mas vai muito mais longe. Pois não somente dá conforto aos pobres; promete que, conforme a devoção que lhe dedicarem, os pobres se tornarão ricos. Seu dossiê de realizações - não haja dúvida - é formidável, em parte porque ele é um deus exigente e rigorosamente monoteísta. Seu primeiro mandamento é conhecido: 'Não terás outros deuses diante de mim'. Isto significa que aqueles que the seguem o caminho devem adequar suas necessidades e aspirações às possibilidades da tecnologia (POSTMAN, 2002, p. 17).
\end{abstract}

O endeusamento da tecnologia parte do princípio de que o progresso da humanidade e a inventividade tecnológica são categoricamente a mesma coisa (POSTMAN, 2002, p. 18). Contudo, a tecnologia que deveria servir ao homem acaba por escravizá-lo. Estão entre as dez mercadorias mais vendidas de todos os tempos os celulares, computadores móveis, consoles e jogos de vídeo game. O mais interessante nesta lista é que são equipamentos com alta taxa de obsoletização. Cada vez mais se abrevia o tempo entre produção e descarte. Mesmo sem utilidade prática, as inovações precisam ser adquiridas porque a atualização simboliza poder, o qual, por sua vez, gera reconhecimento social. Mesmo que o novo equipamento ofereça 


\section{Autนaดูลิ}

ISSN: 1984-6444 | http://dx.doi.org/10.5902/1984644437943

serviços que nunca serão usados, ele precisa ser adquirido, pois, possuir o mais novo, o tecnologicamente mais avançado, é uma importante estratégia de reconhecimento e poder.

Para evitar conclusões apressadas, me adianto e afirmo que a tecnologia pode e deve sim ser usada na educação. Talvez o melhor caminho para lidar com as novas tecnologias é entender que as condições históricas não são as mesmas. De acordo com o filósofo francês Michel Serres, estamos diante de uma geração que pensa, comunica e age de forma muito distinta da nossa. Estamos diante de novas formas de expressão e comunicação, talvez mesmo diante um novo modo cognitivo que exige um novo professor, uma nova relação pedagógica, enfim, novas instituições educativas, preparadas para acolher e atender esse novo ser humano. Serres diz que

Essas crianças, então, habitam o virtual. As ciências cognitivas mostram que o uso da internet, a leitura ou a escrita de mensagens com o polegar, a consulta à Wikipédia ou ao Facebook não ativam os mesmos neurônios nem as mesmas zonas corticais que o uso do livro, do quadro-negro ou do caderno. Essas crianças podem manipular várias informações ao mesmo tempo. Não conhecem, não integralizam nem sintetizam da mesma forma que nós, seus antepassados. Não tem mais a mesma cabeça (SERRES, 2013, p. 19).

Diante dessa nova geração, encontramos os que acreditam que a tecnologia pode salvar a educação. Crescentemente, a tecnologia é vista como a grande e, talvez, única possibilidade de fazer da sala de aula um ambiente próprio para enfrentar os desafios das sociedades contemporâneas. Existem muitos benefícios e possibilidades para a tecnologia na educação, mas, mesmo assim, é preciso estar atento ao uso indiscriminado da tecnologia e desconfiar da promessa de que a tecnologia é a redenção quase milagrosa de todos os problemas e dificuldades enfrentados pela educação na atualidade. A emancipação que buscamos, certamente, tem como um de seus requisitos tanto a familiarização com as possibilidades quanto a resistência ao encantamento exagerado com relação à tecnologia.

A tecnologia não tomou o lugar dos antigos deuses; ela criou, por assim dizer, seus próprios deuses, hoje tão adorados quanto os deuses redentores da antiguidade. O ser humano e o mundo dependem de suas graças e quem não alcança tais graças está perdido, senão ao inferno, pelo menos ao ostracismo social. Os que não têm 


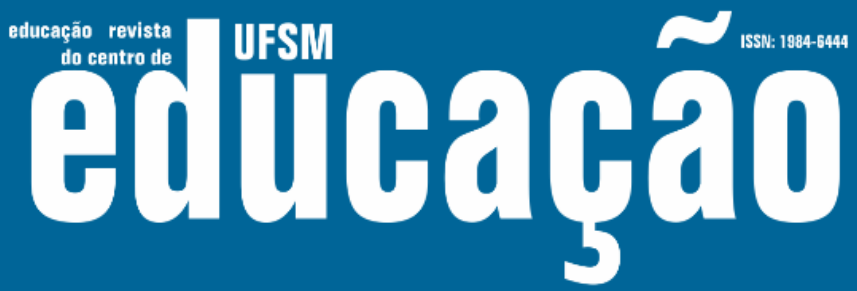

ISSN: 1984-6444 | http://dx.doi.org/10.5902/1984644437943

computador de última geração, quem não anda com seu smartphone ou seu Tablet, são considerados seres estranhos que não se dão conta que os tempos mudaram. Não se aperceberam que hoje o céu ao qual se aspira está ocupado por novos deuses que devem servir de exemplo e modelo às gerações mais jovens.

De modo geral, a confiança depositada na tecnologia é tão grande que é muito difícil argumentar contra os seus defensores. O principal argumento em defesa da tecnologia na educação concentra-se na afirmação de que hoje os educandos têm mais acesso a informação fora da sala de aula do que dentro dela. E nisso concordamos. Contudo, tal situação não permite concluir que as instituições educativas são hoje dispensáveis. Pelo contrário, talvez nunca na história da humanidade elas tenham sido tão necessárias. A razão é simples: oferecer informação ao educando - basicamente as máquinas fazem - é apenas uma das tarefas da educação. Tão, ou mais importante, é trabalhar pedagógico/formativamente o fato e o teor desse novo modus de difusão/apropriação do conhecimento.

Neste sentido, é de extrema relevância distinguir entre informação e formação. O que recebemos todos os dias, na forma de informações pelos jornais, internet, rádio, televisão ou outros meios de comunicação é o que chamamos de informação. Nesse contexto, e com a irrupção abissal das cadeias de difusão, as informações tendem a ser entendidas e avaliadas a partir de seu caráter de novidade, impacto, quantidade e agilidade. Estes elementos, de certa maneira formais e exteriores, reforçam a necessidade de práticas pedagógicas crítico-reflexivas que trabalhem a relação desse enorme fluxo de informações com o ser humano em processo de educação. Trata-se do desenvolvimento de competência com o sentido de criticidade e autonomia que, numa palavra, se designa como formação. É um processo complexo e amplo de investigação, análise, reflexão, confrontação, verificação, organização, seleção e estruturação das informações. Só assim, o grande volume de informações pode alcançar um sentido formativo.

Além disso, é preciso ter claro que todo o tipo de tecnologia não apenas nos oferece benefícios. Ela também toma algo de nós, alterando nossos modos de vida, nossos hábitos, nossos relacionamentos e nossos pensamentos. Como ignorar que com o advento dos pequenos computadores de mão as pessoas deixaram de 


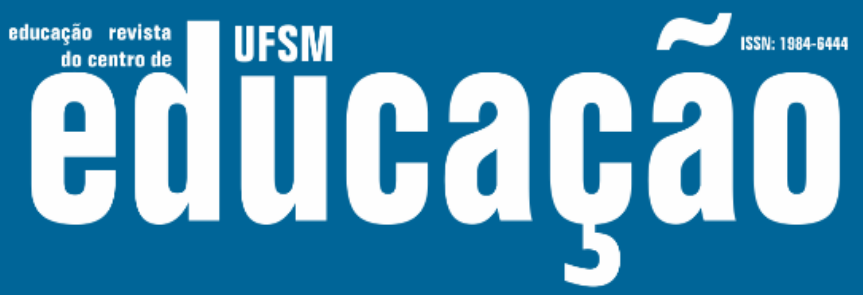

ISSN: 1984-6444 | http://dx.doi.org/10.5902/1984644437943

conversar na rua, no ônibus, na mesa de jantar e, inclusive, nas próprias instituições educativas? De fato, o uso da tecnologia na educação pode ser importante, mas é preciso discutir, inclusive em sala de aula, suas vantagens e riscos. Talvez seja mais necessário questionarmos quais são seus efeitos sobre os nossos hábitos, nossa mente e nosso modo de nos relacionarmos com o mundo e com as pessoas.

Negar o acesso à tecnologia aos educadores e educandos seria aderir a uma absurda estratégia de exclusão tecnológica e social. Precisamos pensar como as novas tecnologias podem contribuir para formação integral do indivíduo. Ou seja, a tecnologia já está aí e seu acesso se dissemina muito rápido. Computadores nas salas de aula vêm se tornando tão comuns quanto cadernos e livros. Existem vários programas estatais empenhados em disponibilizar na educação pública os chamados laboratórios de informática. Outros programas já estão distribuindo tablets aos professores e alunos. Em muitos casos, a disponibilização destas máquinas tem mais um efeito publicitário que educativo. Fornecer gratuitamente ou a preço reduzido tablets ou notebooks traz a mensagem que a instituição tem nível de excelência. Servem, portanto, de isca para atrair clientes e consumidores e pouco têm a ver com o interesse educativo. O mesmo vale, em termos de propaganda política, para governos que disponibilizam recursos eletrônicos para escolas que sequer têm a infraestrutura para seu uso. De resto, em nenhum momento, se devem esquecer os interesses multibilionários daqueles que fabricam ou detêm as patentes destes equipamentos. Por isso, é muito importante questionar, para além dos seus benefícios, quais são os bloqueios que a tecnologia pode trazer para a emancipação.

Precisamos entender que a tecnologia deve estar a serviço do homem e não o inverso. Alan Kay, com passagens pela Apple Computer, pela HP e pela Walt Disney Imagineering, ainda na década de 90, quando trabalhava na Apple e participava da equipe que criou e vendeu o primeiro computador pessoal, afirmava que os problemas que as escolas não conseguem resolver sem os computadores, também não conseguirão solucioná-los com eles. Educação em seu sentido mais humano, profundo e denso, ou seja, no sentido de formar pessoas em sua subjetividade e sociabilidade, exige das instituições educativas mais que um laboratório de informática ou de ciências. Se pretendemos que este ideal formativo ainda continue sendo o 


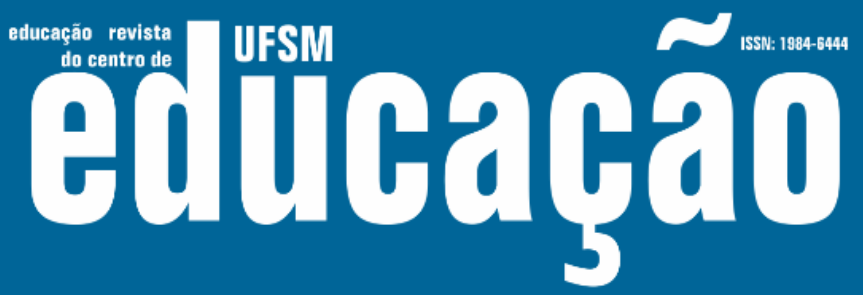

ISSN: 1984-6444 | http://dx.doi.org/10.5902/1984644437943

horizonte da educação escolar, os novos recursos e técnicas têm que ser integrados a tais objetivos, inclusive aproveitando o potencial formativo das novas tecnologias.

Este processo inclui, também, a conscientização do risco de seu uso, como ocorre, só para citar um exemplo, no caso da socialização das tecnologias. Basta ver que os benefícios da tecnologia não são distribuídos igualmente aos membros da sociedade. A disponibilização desses benefícios dentro das instituições educativas privadas também é muito diferente daquele usual nas instituições públicas. $\mathrm{Na}$ verdade, vale a pergunta: quem aprende mais, o educando que tem à sua disposição um computador ou aquele que precisa aprender a dividir um computador com os colegas? De toda forma, como a tecnologia não é distribuída igualmente, ela cria um grupo de vencedores e um de perdedores, um grupo de incluídos e um grupo de excluídos.

Outra questão está relacionada ao papel do educador no contexto da educação mediada tecnologicamente. Geralmente, quando não se pensa com seriedade o uso da tecnologia na educação, o papel do educador é reduzido a de instrutor. Isso significa transformar o processo educativo num processo formal e técnico, desconectado de toda a história do educador e do educando. É como se o educando não devesse se preocupar com o seu entorno, pois tendo a tecnologia em suas mãos ele, supostamente, é capaz de tudo.

Existem autores que se posicionam contra o que definem como determinismo tecnológico. Vilém Flusser é um deles. Ele usa uma metáfora entre o determinismo e um carro em movimento que é muito interessante para alertar sobre o perigo do determinismo tecnológico. De acordo com essa metáfora, o determinismo tecnológico é como um carro em movimento que não necessita de direção ou de desvios, que corre livremente, automaticamente e, neste meio tempo, pode atropelar a humanidade caso ela veja tarde demais que o desenvolvimento prometido não foi exatamente o obtido (FLUSSER, 2007, p. 74). No caso da educação, o atropelamento resultante do mau uso das máquinas eletrônicas pode ser verificado na superficialidade e pequenez dos textos produzidos pelos educandos, na resistência a leituras mais profundas e mais complexas, no prejudicado desenvolvimento cerebral e na impaciência e indisciplina nas salas de aula. 


\section{N Usin

ISSN: 1984-6444 | http://dx.doi.org/10.5902/1984644437943

A tecnologia é a extensão do braço humano. Ou seja, criamos tecnologia para fazer aquilo que fisicamente não conseguiríamos fazer. Porém, damos pouca atenção ao fato de que a tecnologia transforma nosso modo de ser, de pensar e de agir. Basta fazermos uma retrospectiva e observar o quanto mudamos desde a invenção do computador e da Internet. Nossa capacidade de concentração, por exemplo, já não é a mesma. Nossos relacionamentos também mudaram. Nicholas Carr, em seu livro $A$ geração superficial - $O$ que a internet está fazendo com os nossos cérebros, amparado em Marshall Mcluhan, defende que as TICs estão modificando significativamente o nosso cérebro:

O conteúdo do meio importa menos do que o próprio meio na influência sobre o nosso modo de pensar e de agir. Como nossa janela para o mundo e para nós mesmos, um meio popular molda o que vemos e como vemos - e, por fim, se o usarmos o suficiente, modifica quem somos, como indivíduos e como sociedade [...] O meio faz a sua mágica ou o seu feitiço no próprio sistema nervoso (CARR, 2011, p. 13).

Para dar força aos seus argumentos, Carr (2011, p. 13) recorre aos estudos e pesquisas da Neurociência. Nessas pesquisas ele se deparou com a neuroplasticidade. Os pesquisados que trabalham com esse conceito, argumentam que o cérebro possui a capacidade de se adaptar ou de se reprogramar. Pesquisas com cobaias humanas que haviam sofrido algum tipo de trauma, desde a perda de um membro do corpo ou de um dos sentidos, mostraram que o cérebro procura novos caminhos para abrandar o trauma. É o caso daqueles que perdem a visão e aperfeiçoam o olfato, a audição e ou o tato:

O cérebro não é a máquina que antigamente pensávamos que era. Embora diferentes regiões do cérebro estejam associadas com diferentes funções mentais, os componentes celulares não formam estruturas permanentes ou desempenham papéis rígidos. Mudam com as experiências, circunstâncias e necessidades. Algumas das mudanças mais extensas e notáveis ocorrem em resposta a danos do sistema nervoso. Experimentos mostram, por exemplo, que quando uma pessoa fica cega, a parte do cérebro que era dedicada ao processamento de estímulos visuais - o córtex visual - não se apaga simplesmente. Ela é rapidamente requisitada pelos circuitos usados para o processamento auditivo (CARR, 2011, p. 49).

Experimentos com jovens que cresceram com a internet mostram que eles não conseguem se concentrar por mais de 7 minutos em média. Isso ocorre porque a internet tem um funcionamento completamente diferente da leitura de um livro. As 


\section{Autuaŗão}

ISSN: 1984-6444 | http://dx.doi.org/10.5902/1984644437943

redes sociais, os Blogs e o Twitter não veiculam textos longos. Pelo contrário, no caso do Twitter, o número de letras ou caracteres é limitado propositadamente. Outro exemplo são as redes tipo YouTube e Instagram que substituem o texto pelo vídeo e pela foto. Além disso, visto que navegar na Internet não exige concentração, os jovens costumam fazer mais de uma atividade ao mesmo tempo; o que não significa que as façam com a mesma qualidade. Vivemos o que podemos chamar de crise da inteligência.

Para os fins desse artigo, vamos assumir a definição clássica de inteligência. Do latim intellectus, inter e lec, significa escolher entre, ou intus e lec, que significa escolher dentro. Inteligência é a faculdade que tem o espírito de pensar, conceber, compreender. Dessa definição podemos extrair pelo menos duas consequências importantes: primeiro, inteligência implica na capacidade de escolher e, segundo, fazer uso dela significa mobilizar as faculdades que nos ajudam escolher.

Quer dizer, para escolher precisamos conhecer, compreender, raciocinar, pensar e interpretar. Entre as faculdades que constituem a inteligência, também está o funcionamento e uso da memória, do juízo, da abstração, da imaginação e da concepção. Parte-se do pressuposto que um ser inteligente faz a escolha sempre amparado por essas faculdades, pois para a escolha da melhor e mais adequada oportunidade, entre as várias opções, uma pessoa precisa avaliar ao máximo todas as vantagens e desvantagens das hipóteses, necessitando para isso da capacidade de raciocinar, pensar e compreender, ou seja, a base do que forma a inteligência.

O problema é que além da internet oferecer uma falsa sensação de conhecimento, pois, por sua mediação, apenas possuímos acesso à informação, ela também modifica o modo como lidamos com o mundo e com os outros. A capacidade de concentração e atenção está prejudicada. Ler um livro, por exemplo, exige um tipo de concentração que a internet não requer. Afinal, é preciso se desligar do mundo e "entrar" na lógica do livro para entendê-lo. E aqui talvez se encontre a principal diferença, pois a leitura do livro, diferentemente da internet, mobiliza pensamento, memória, abstração e imaginação: 


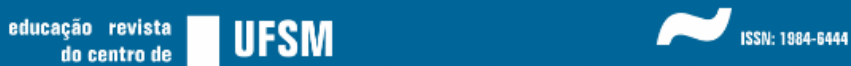 Eulloabुa}

ISSN: 1984-6444 | http://dx.doi.org/10.5902/1984644437943

O que era tão notável em relação à leitura do livro é que a concentração profunda estava combinada com a decifração altamente ativa e eficiente do texto e a interpretação do significado. A leitura de uma sequência de páginas impressas era valiosa não apenas pelo conhecimento que os leitores adquiriam das palavras do autor, mas também pelo modo como essas palavras despertavam vibrações intelectuais no interior das suas mentes. Nos silenciosos espaços abertos pela leitura prolongada, sem distrações, de um livro, as pessoas criavam as suas próprias associações, faziam suas próprias inferências e analogias, e cultivavam suas próprias ideias. Pensavam profundamente, enquanto liam profundamente (CARR, 2011, p. 95).

Não são poucas as pesquisas que mostram os efeitos nocivos da internet para o cérebro e para a nossa personalidade. Com as novas tecnologias pensamos e nos comportamos de forma diferente. Será que estamos aproveitando nosso cérebro naquilo que de melhor ele pode nos oferecer? Será que estar conectado significa estar junto com os outros? Essas questões precisam ser abordadas pela educação, sob pena de não se levar a sério as transformações em curso no contexto atual.

O trabalho da psicóloga e socióloga americana Sherry Turkle (2012) contribui muito para esse debate. Professora naquele que é considerado o maior instituto de tecnologia do mundo, o Instituto de Tecnologia de Massachusetts - MIT, ela tem pesquisado e publicado sobre como a relação dos seres humanos com as novas tecnologias afeta sua relação com o mundo e com os outros. Seu livro Alone Together: Why we expect more from technology and less from each other (2012) (traduzido livremente como Sozinhos juntos: porque esperamos mais da tecnologia e menos dos outros) mostra como a tecnologia está mudando a forma como as pessoas se relacionam umas com as outras e constroem suas vidas internas. Sua preocupação é de ordem psicológica e sociológica.

Nos seus livros anteriores, Turkle enfatiza a profusão de oportunidades para cultivar a identidade que os computadores e as redes sociais oferecem para as pessoas. Por outro lado, em Alone Together (2012), ela nos apresenta uma visão mais pessimista, argumentando que as novas tecnologias têm feito da conveniência e controle uma prioridade enquanto reduzem as expectativas que temos uns dos outros. Quer dizer, as novas tecnologias nos oferecem a sensação de controle. Podemos escolher o que queremos ver, com quem falamos, quando falamos. Temos a sensação de que o mundo está a um clique e sob nosso controle. 


\section{F HEM Eutinará

ISSN: 1984-6444 | http://dx.doi.org/10.5902/1984644437943

Podemos ter uma conversa nas redes sociais? Podemos. Mas nas redes sociais temos o controle. Podemos pensar, escrever e apagar se acharmos conveniente. Numa conversa real, não temos total controle sobre o que comunicamos. Além disso, uma vez comunicado, não se pode voltar atrás e apagar. O computador e as novas tecnologias da informação e comunicação nos oferecem a oportunidade de nos apresentar de forma maquiada. Redigimos, apagamos e editamos o que somos. Toda a riqueza presente nas relações humanas é ignorada.

As relações humanas são confusas e exigentes. E nisso está sua riqueza. De acordo com Turkle, nós estabelecemos conversas para aprendermos a conversar com nós mesmos. Nesse sentido, fugir de uma conversa ou de uma relação no mundo real pode comprometer a nossa capacidade de autorreflexão. Do ponto de vista da educação, essa capacidade é fundamental para o desenvolvimento das crianças. $O$ modo como estamos nos apropriando dessas novas tecnologias nos faz querer evitar o contato e a convivência no mundo real. Afinal, no mundo virtual podemos escolher a hora, a rede, as pessoas e o tempo disponível para uma conversa.

Para Turkle, com as promessas das novas tecnologias, nós aprendemos a esperar mais da tecnologia do que dos outros seres humanos. Isso acontece porque vivemos um dilema: não queremos estar sozinhos porque temos medo da solidão. Para dar conta da solidão, desenvolvemos tecnologias que nos oferecem a impressão de estar conectados. Mas isso ocorre apenas no mundo virtual. Uma amizade no mundo real é um relacionamento exigente. No mundo virtual, pelo contrário, as amizades são editadas e não precisam de intimidade.

Estar verdadeiramente sozinho é fundamental para a formação da identidade psíquica. Turkle defende, no entanto, que nos dias atuais nos isolamos com a falsa sensação de que estamos conectados. Quer dizer, nem estamos verdadeiramente sozinhos e nem estamos verdadeiramente conectados. Nos relacionamos com essas máquinas virtuais como se elas fossem outras 'pessoas', porém, 'pessoas' que estão sob o nosso controle. Com esse controle, nos aproximamos mais e mais do objetivo de acalmar nosso medo de ficar sozinhos.

Dessa tese Turkle tira uma conclusão fundamental: se não formos capazes de estar verdadeiramente sozinhos, então estaremos, efetivamente, cada vez mais 


\title{
usm Eutibabat

ISSN: 1984-6444 | http://dx.doi.org/10.5902/1984644437943

sozinhos. É preciso aprender a ficar sozinho. Essa experiência possibilita o desenvolvimento da autorreflexão. Desenvolvendo essa capacidade, seremos capazes de estabelecer uma relação mais consciente com esses aparelhos. Zoë Neill Readhead, filha de A. S. Neil, fundador da Escola de Summerhill, foi também aluna, mãe e é diretora de uma das democracias educacionais mais antigas do ocidente. No seu livro, intitulado Summerhill Hoy, Readhead (2012, p. 17) nos fala da importância de estar sozinhos para a formação das novas gerações:

\begin{abstract}
Esta es una de las virtudes de Summerhill: permite a la gente estar a solas y tener su espacio. A la mayoría de adultos les gusta estarlo alguna vez, pero para los niños hay pocas oportunidades, porque normalmente aparece algún mayor preocupándose por ellos y queriendo ofrecer su ayuda. A veces está bien no tener ayuda ninguna, simplemente estar en tu propio espacio.
\end{abstract}

Nesse sentido, Turkle defende que devemos voltar a conversar realmente. Falar uns com os outros. Na conversa real, erramos, tropeçamos e dizemos coisas das quais nos arrependemos. Isso revela quem somos verdadeiramente. Diferentemente do mundo virtual e conveniente, na vida real temos de enfrentar conversas e relacionamentos que nos incomodam. Mas essa é a riqueza humana. Nessas experiências podemos conhecer os outros e conhecer mais a nós mesmos.

Estar conectado o tempo todo nos faz experimentar um falso sentimento de não estarmos sozinhos. Mas são os relacionamentos reais que possibilitam a experiência de apreciar e estimar os outros pelo quê eles são de verdade. Para Honneth essa experiência é fundamental. Do contrário, estaríamos usando os outros como instrumentos enquanto são úteis, substituindo-os, em seguida, por outros mais convenientes para o fortalecimento da nossa frágil identidade. Sobre o desafio com as novas tecnologias, argumenta Honneth (2013, p. 559-560):

Certamente é tarefa do ensino escolar preparar técnica e socialmente os alunos para o uso dessa nova mídia, mas o enfrentamento conjunto de suas consequências históricas nem de longe deve se esgotar nisso. Parece-me, além disso, necessário averiguar em conjunto, na verificação experimental do surgimento de temas e conhecimentos digitalmente disseminados, onde se encontram, além dos potenciais, também os limites e as ameaças da nova mídia [...] As alunas e os alunos deveriam ser preparados, por meio da utilização cooperativa do computador - portanto, inteiramente de acordo com o que preconizava Dewey - , a fazer uso mais tarde, de maneira autônoma, dos novos instrumentos da formação da vontade política. 


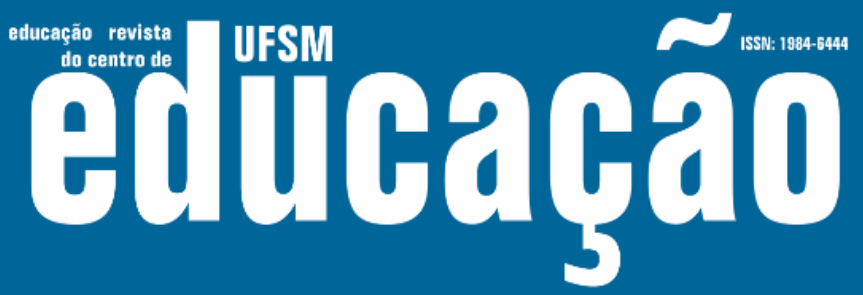

ISSN: 1984-6444 | http://dx.doi.org/10.5902/1984644437943

Honneth entende que as novas tecnologias estão não apenas desabilitando nossa capacidade de pensar criticamente, mas também nossa capacidade de cooperar. De acordo com o autor, outro grande desafio para essas instituições está na convivência cada vez mais próximas de crianças com crenças, valores, objetivos e culturas diferentes. Da forma como estão organizadas as nossas instituições educativas, acentuamos o individualismo e nos isolamos das pessoas ou grupos que não partilham dos mesmos valores e objetivos.

Como se vê, são muitos os estudos que indicam que vivemos uma crise da inteligência1. Quer dizer, estamos diante de uma geração que está desabilitando sua capacidade de pensar crítica e autonomamente e também de cooperar. Nesse sentido, nós educadores precisamos pensar cuidadosamente a relação entre tecnologia e educação para além de posições radicais. Além disso, é preciso trabalhar para reverter esse processo em marcha. Mas quais seriam as possibilidades para esse enfrentamento?

\section{Possibilidades de enfrentamento dos desafios postos pela crise da inteligência}

A primeira medida que nós educadores precisamos assumir é o reconhecimento que estamos diante de um problema com sérias consequências. Percebemos que existem poucas pesquisas que apontam para essas mudanças. A maioria das pesquisas encontradas destacam os apenas os benefícios das novas tecnologias da informação e comunicação. Além disso, quem procura levantar a voz contra as novas tecnologias é visto como louco.

Tenho destacado que não se trata de escolher entre um mundo com ou sem as novas tecnologias. Esse mundo já está posto. Contudo, especialmente na educação, devemos ter o cuidado de analisar e pensar estrategicamente o uso dessas tecnologias. O problema, muitas vezes, é que a urgência das nossas dificuldades em educação nos faz aceitar proposições antes mesmo de verificar sua veracidade.

O mais perigoso é que estamos diante de um fundamentalismo tecnológico. Os profissionais da educação estão aceitando acriticamente o discurso em defesa do uso 


\section{Authabูão}

ISSN: 1984-6444 | http://dx.doi.org/10.5902/1984644437943

das novas tecnologias. Talvez possamos dialogar com outras áreas do conhecimento como, por exemplo, a psicologia e a neurociência. Essas áreas apresentam pesquisas que revelam como essas tecnologias transformam nossas ações e pensamentos. Não se trata de fazer o caminho inverso e proibir o uso das novas tecnologias, mas de pensar e analisar criticamente sua utilização e entender que são meios e não o fim da educação.

Não podemos nos esquecer que as instituições educacionais são criações humanas. Como tais, tem uma finalidade. Da nossa perspectiva, a finalidade dessas instituições está em criar as condições para que as novas gerações desenvolvam sua inteligência e conquistem a autonomia moral, intelectual e política. Ou seja, a emancipação é o objetivo último da educação. Educamos porque desejamos que cada um alcance uma vida que possa chamar de sua.

A segunda medida é reconhecer que as novas tecnologias têm desabilitado algumas das nossas mais importantes capacidades. Diferente das tecnologias anteriores, essas novas tecnologias escravizam as novas gerações. Não nos esquecemos que o livro, o papel, o lápis também são tecnologias. No entanto, diferente das novas tecnologias, o livro, o lápis e o papel não nos tornam dependentes. Para exemplificar, uma das clinicas mais caras do mundo foi criada exclusivamente para atender viciados nessas novas tecnologias e na internet. Com diárias de mais de $\mathrm{R} \$ 5,4$ mil, a clínica Paradigm funciona em São Francisco nos Estados Unidos e tem o objetivo de desconectar crianças e jovens.

Também nos EUA, ex-funcionários do Facebook, Google, IBM e outras importantes empresas do vale do silício, criaram o Center for Humane Technology. Qual a finalidade desse grupo? Alertar para o que eles chamam de sequestro das nossas mentes. Nossa sociedade, dizem os homens que ajudaram a criar essas novas tecnologias, está sendo sequestrada. O que começou como uma corrida para monetizar nossa atenção agora está erodindo os pilares de nossa sociedade: saúde mental, democracia, relações sociais e nossos filhos.

O destaque fica por conta do fato de que essas novas tecnologias sequestram nossa atenção. Pesquisadores americanos estão chamando isso de Brain Drain, que é a capacidade do celular de drenar atenção do cérebro. Uma pesquisa publicada por 


\section{工 Eulloabुa}

ISSN: 1984-6444 | http://dx.doi.org/10.5902/1984644437943

Adrian Ward, Ayelet Gneezy, Kristen Duke e Maarten W. Bos (2017) da Universidade do Texas ${ }^{2}$, realizada com mais de 500 estudantes, mostra que mesmo no silencioso e com a tela virada para baixo, sem notificações e sem toques, a simples presença no celular tirou a capacidade de concentração dos estudantes, que tiveram um desempenho pior em testes cognitivos do que aqueles que deixaram seu celular em outro ambiente.

Desde o início do texto defendemos que estamos vivendo uma crise da inteligência. Uma das razões principais é que não é possível desenvolver a inteligência satisfatoriamente sem atenção e concentração. Umas das falácias defendidas pelos defensores do uso indiscriminado das novas tecnologias na educação parte do pressuposto de que elas desenvolvem a capacidade de dividir a atenção. Alguns, inclusive, chamam essa geração de multitarefa, pois seriam capazes de dividir a atenção com vários equipamentos e trabalhos.

É interessante notar, como já afirmava o escritor Arthur C. Clarke, que toda tecnologia suficientemente avançada é indiscernível da magia. Sabemos que na mágica o que importa é a aparência e não a realidade. O truque está em mostrar o que deve ser visto e não o que é real. No caso das novas tecnologias, a magia está em mostrar seus benefícios e não o que ela nos toma cotidianamente. Mostra como podemos estar conectados, informados, mas esconde como ela suga nossa atenção, concentração e, portanto, a capacidade de pensar e analisar criticamente as informações que estão acessíveis. Sobre isso diz Sibilia:

[...] a sociedade informacional não conecta, mas tende a desligar, dificultando as possibilidades de dialogar ou de compor uma experiência junto com os demais. Esse efeito se evidencia nos usos mais habituais do chat pela internet, que se configuram como mera "função fática", por exemplo: algo parecido com o que costuma acontecer com boa parte das mensagens de texto ou na utilização do celular em geral, assim como do Twitter e do Facebook, de blogs e fotologs, e até dos vídeos divulgados no YouTube. Nesses casos, o canal não está a serviço da mensagem, mas ao contrário: serve tão somente como algo a que é possível nos agarrarmos para sobreviver à dispersão, mantendo-nos conectados (SIBILIA, 2012, p. 186187).

Essa segunda medida implica, talvez, na tarefa mais dura de todas. É preciso ensinar nossas crianças e jovens a desconectar-se dessas novas tecnologias. Não é 


\section{THEM Eulloarao

ISSN: 1984-6444 | http://dx.doi.org/10.5902/1984644437943

uma tarefa simples, pois, como dizem os próprios criadores dessas tecnologias e redes sociais ${ }^{3}$, tudo é feito para captar nossa atenção e não devolver mais. Desde o designer até os algoritmos mais avançados, tudo é pensando para o indivíduo incorporar no seu corpo aquela nova tecnologia. Diante disso, e por mais difícil que seja esse enfrentamento, devemos assumir a responsabilidade de mostrar que o mundo real é muito mais interessante e admirável que o mundo virtual.

A terceira medida está no fato de que esses dispositivos móveis estão dissolvendo a necessidade histórica de dividir instrumentos comuns. Ou seja, estamos desabilitando nossa capacidade de trabalhar cooperativamente. Estamos diante de um fenômeno social e cultural de individualização. Richard Sennett (2013) costuma dizer em seus textos que a sociedade moderna está desabilitando as pessoas na condução da vida cotidiana. Cooperar é uma dessas capacidades que estão sendo desabilitadas. Axel Honneth (2013) é ainda mais agudo ao dizer que a verdadeira autonomia só é conquistada depois de aprender a cooperar. Precisamos cooperar para enfrentar os conflitos e desafios típicos das nossas sociedades. Contudo, vivemos numa sociedade com a tendência de minimizar os conflitos e as diferenças. Sobre isso diz Sennett (2013, p. 19):

A sociedade moderna está gerando um novo tipo de caráter. É o tipo de pessoa empenhada em reduzir ansiedades provocadas pelas diferenças, sejam de natureza política, racial, religiosa, étnica ou erótica. O objetivo da pessoa é evitar qualquer sobressalto, sentir-se o menos estimulada possível por diferenças profundas [...] 'Tudo é basicamente igual' expressa essa visão de mundo que busca a neutralidade. $O$ desejo de neutralizar toda diferença, de domesticá-la, decorre (é pelo menos o que tentarei demonstrar) de uma angústia em relação à diferença, conectando-se com a economia da cultura global de consumo.

Estamos perdendo a capacidade de lidar com a diferença e com tudo que ela origina. A esperança que tínhamos com as novas tecnologias da informação e comunicação está em xeque. Como disse anteriormente, nas redes sociais somos o que nos convém. Na esfera pública real não temos as opções bloquear, apagar, colar e editar. É verdade que frente à frente podemos também mentir, omitir ou ser indiferentes. Mas o fato de estar com outra pessoa nos obriga a um relacionamento que implica uma série de movimentos e sentimentos que são, na maioria das vezes, espontâneos e não mecânicos ou editados. As redes sociais não estimulam a 


\section{Authabูão}

ISSN: 1984-6444 | http://dx.doi.org/10.5902/1984644437943

cooperação como esperávamos. Pelo contrário, elas incitam ao individualismo e comprometem a capacidade de lidar com o diferente. Nos isolamos em nosso mundo virtual e tudo o que não está de acordo com ele ignoramos ou incorporamos.

A capacidade de cooperar é fundamental. Para o bem da democracia, as novas gerações precisam aprender a trabalhar com os outros e oferecer à comunidade suas melhores habilidades. Falar de cooperação num contexto cada vez mais capitalista, materialista, instrumentalista individualista e utilitarista pode até parecer estranho, mas é preciso lutar pelo desenvolvimento dessa capacidade. Afinal, os desafios relacionados às sociedades complexas e plurais exigem soluções coletivas e não individualistas.

Daí a importância de o ambiente educacional criar espaços e práticas capazes de estimular a participação ativa dos educandos em sua própria formação. Isso significa, em primeiro lugar, no caso das novas tecnologias, de mostrar que eles precisam aprender a dividir essas tecnologias. Não se trata de pegar computadores, celulares e proibir o seu uso. Mas de limitar e de ofertar a oportunidade de aprender a usar essas novas tecnologias de maneira cooperativa e não individualista.

Por outro lado, devemos estimular outras práticas. As assembleias por exemplo. Elas podem ser espaços privilegiados onde os mais jovens podem alcançar o autorrespeito, pois oferecem a todos a oportunidade equitativa de participarem da vida e da organização da instituição educativa da qual fazem parte. Além disso, elas também podem oferecer a oportunidade de cada um apresentar e ampliar suas capacidades individuais que podem contribuir para o aprofundamento das relações e da organização do ambiente educacional.

Se queremos assumir um compromisso real com o futuro da democracia, é urgente criarmos espaços reais em nossas instituições educativas que convidem as novas gerações a saírem do espaço público virtual. Nossas crianças e jovens estão submersos nas redes sociais como se elas fossem a vida real. Recentemente o mais famoso fundador do Facebook, Mark Zuckerberg, foi convidado a depor no congresso americano. Entre outras preocupações, como a privacidade dos dados dos usuários, estava a discussão da influência interna e externa das redes sociais nas eleições americanas. No Brasil, o atual presidente, Jair Bolsonaro, começou a ser eleito na 


\section{Autuaŗão}

ISSN: 1984-6444 | http://dx.doi.org/10.5902/1984644437943

primeira década desse novo milênio. Com o surgimento das redes sociais associadas as novas tecnologias, fomos criando as condições necessárias para uma eleição decidida sem reflexão e crítica política. Afinal, como mostra a pesquisa de Juliano Spyer (2018), as redes socais servem mais a conservação do que ao debate e reformulação de ideias e posições. O espaço das redes tem se constituído numa guerra onde os soldados não tem rosto, não tem compromisso com a verdade e com a história. Trata-se apenas de usar de todas as estratégias possíveis para convencer os outros da sua opinião. Notícias falsas, dados de pesquisas que não existem, inversão de fatos históricos e outras tantas formas de criar uma "verdade".

Muitos dos nossos jovens não são capazes de classificar o que verdadeiro e o que é falso. $E$ isso não ocorre porque eles decidiram que assim seria. Ocorre porque essas tecnologias não Ihe ajudam a desenvolver as capacidades de ler atentamente, de se concentrar, de classificar e de analisar criticamente as informações disseminadas nessas redes. A posição política de cada um pode ser defensável, criticável e aceitável. Mas para isso nossos jovens precisão desenvolver as capacidades e habilidades necessárias para decidirem autonomamente sobre o que desejam politicamente.

Nossas instituições educacionais precisam estar preparadas para desenvolver espaços, estratégias e alternativas às redes sociais. A escola com espaço público precisa estar pronta para convidar nossas crianças e jovens a discutir, pensar e refletir frente a frente seus problemas e desafios. Não podemos olhar para eles submersos e capturados por essas tecnologias e cruzar os braços. Cafés com leitura e discussão de textos, assembleias, clubes de cinema, atividades culturais e artísticas, passeios pela comunidade e pela cidade ou mesmo uma disciplina de concentração como propõe Christoph Türcke (2016, p. 87). Existem muitas maneiras de capturar a atenção ativa. É uma tarefa simples? Certo que não. Mas, como geração adulta, não podemos nos desresponsabilizar e deixar de criar as condições para que as novas gerações conquistem a autonomia intelectual, moral e física. 


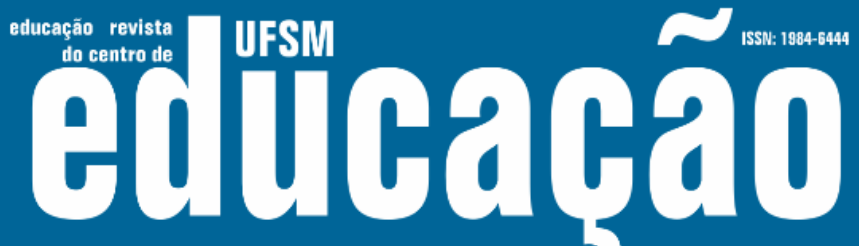

ISSN: 1984-6444 | http://dx.doi.org/10.5902/1984644437943

\section{Considerações finais}

Precisamos com urgência enfrentar o que chamamos de crise da inteligência. É importante destacar que não se trata de dizer que essa nova geração é menos inteligente que as anteriores. Trata-se de reconhecer que essa geração não está desenvolvendo satisfatoriamente as suas capacidades e habilidades e, portanto, a sua inteligência. A educação, parafraseando Adorno, deve servir para que Auschwitz não se repita. Se queremos evitar toda forma de barbárie, é preciso reconhecer que estamos diante de um desafio muito difícil, mas que requer nosso compromisso com as novas gerações e com o desenvolvimento da democracia,

Também é importante destacar que não é responsabilidade das novas gerações essa crise da inteligência. Na educação, a responsabilidade é sempre da geração adulta. Somos nós que devemos criar as condições institucionais para essas crianças e jovens serem tudo o que podem ser. Não podemos aceitar acriticamente 0 uso das novas tecnologias como se esse uso não estivesse desenvolvendo uma série de obstáculos à conquista da autonomia.

Somos dependentes tecnológicos. Ao entrar numa sala, espaço público, a primeira coisa que procuramos é sinal de internet e uma tomada para carregar o celular. Os programas para tratamento e abandono de vícios afirmam que a primeira atitude é o reconhecimento sincero do vício. Sem esse reconhecimento, não é possível avançar. Nesse sentido, a primeira atitude que precisamos desenvolver e admitir nosso vício na internet e nas novas tecnologias. Sem essa atitude honesta outras medidas não serão possíveis.

Se quisermos recuperar capacidades como concentração, atenção e cooperação, então teremos que nos dispor a participar de atividades com as quais não estamos mais acostumados. Tal qual um viciado precisa passar por uma série de desafios até se libertar do vício, precisamos também ajudar as novas gerações a experimentarem outras formas de conhecer o mundo que não através do Google e das redes sociais. Nossas instituições educacionais precisam se reinventar como espaços de encontro, de diálogo, de produção de pensamento e de experiências capazes de contribuir para a edificação de uma vida verdadeiramente autônoma. 


\section{Dism Eutlaghat}

ISSN: 1984-6444 | http://dx.doi.org/10.5902/1984644437943

Não podemos ignorar que a essência das instituições educativas consiste no relacionamento entre docente e discente, ou seja, entre pessoa e pessoa. Mas essa relação corre o risco de ficar efetivamente comprometida sempre que se abandone cegamente à idolatria tecnológica. Essas instituições devem, sem dúvida, introduzir as novas tecnologias em todos os seus níveis, mas deve também assegurar aquilo que ser humano tem produzido com a cultura escrita ao longo de dois milênios e meio de história. Parafraseando Hannah Arendt, pensar o uso das novas tecnologias significa assumir que amamos o mundo e que nos responsabilizamos por ele por todas as vidas que nele habitam.

\section{Referências}

ADORNO, Theodor. Educação e emancipação. São Paulo: Paz e Terra, 2006.

BOS, Maarten W.; DUKE, Kristen; GNEEZY, Ayelet; WARD, Adrian F. Brain Drain: The Mere Presence of One's Own Smartphone Reduces Available Cognitive Capacity. In: Journal of the Association for Consumer Research, v. 2, n. 2, 2017. Disponível: https://www.journals.uchicago.edu/doi/pdfplus/10.1086/691462. Acesso em 12 nov. 2017.

CARR, Nicholas. A geração superficial: o que a internet está fazendo com os nossos cérebros. São Paulo: Agir, 2011.

FLUSSER, Vilém. O mundo codificado: por uma filosofia do design e da comunicação. Organizado por Rafael Cardoso. São Paulo: Cosac Naify, 2007.

HEIDEGGER, Martin. A questão da técnica. In: Scientiæ zudia, São Paulo, v. 5, n. 3, p. 375-398, 2007.

HONNETH, Axel. O eu no nós: reconhecimento como força motriz de grupos. In: Sociologias, Porto Alegre, ano 15, n.33, p. 56-80, 2013.

HORKHEIMER, Max. Eclipse da razão. São Paulo: Centauro, 2002.

MORDUCHOWICZ, Roxana. Los adolescentes y las rede sociales: La construcción de la identidade juvenil en Internet. Buenos Aires: Fondo de Cultura Económica, 2012.

POSTMAN, Neil. O fim da educação: Redefinindo o valor da escola. Rio de Janeiro: Graphia, 2002.

SADIN, Éric. La humanidade aumentada: La administración digital del mundo.

Buenos Aires: Caja Negra, 2017. 


\section{N

ISSN: 1984-6444 | http://dx.doi.org/10.5902/1984644437943

READHEAD, Zoë Neill. Summerhill Hoy. Valencia: Litera Libros, 2012.

SENNETT, Richard. Juntos: os rituais, os prazeres e a política de cooperação. Rio de Janeiro: Record, 2013.

SERRES, Michel. Polegarzinha: uma nova froma de viver em harmonia, de pensar as instituições, de ser e de saber. Rio de Janeiro: Bertrand Brasil, 2013.

SIBILIA, Paula. Redes ou paredes: A escola em tempos de dispersão. Rio de Janeiro: Contraponto, 2012.

SPYER, Juliano. Mídias sociais no Brasil emergente: como a internet afeta a mobilidade social. London: UCL Press, 2018.

TÜRCKE, Christoph. Sociedade excitada: filosofía da sensação. Campinas/SP: Unicamp, 2010.

TURKLE, Sherry. Alone Together: Why we expect more from technology and less from each other. Nova York: Perseus Books, 2012.

\section{Correspondência}

Maurício Rebelo Martins - Universidade Federal da Paraíba - Campus Universitário III, R. João Pessoa, S/N, CEP 58220-000, Bananeiras, Paraíba, Brasil.

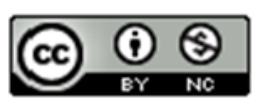

This work is licensed under a Creative Commons Attribution-NonCommercial 4.0 International (CC BY-NC 4.0)

\section{Notas}

\footnotetext{
1 Aqui destacamos apenas alguns. Mas sugerimos como leitura, para quem deseja se aprofundar no tema, as seguintes referências: CARR (2011), MORDUCHOWICZ (2012), SADIN (2017), SIBILIA (2012), SERRES (2013), SPYER (2018), TÜRCKE (2016), TURKLE (2012).

${ }^{2} \mathrm{O}$ artigo no original pode ser acessado no seguinte link: https://www.journals.uchicago.edu/doi/10.1086/691462 3 Veja, por exemplo, a entrevista de Sean Parker, um dos fundadores do Facebook https://www.youtube.com/watch?v=D5-X915iKTc
} 